\title{
Tonsillolith: Not just a stone but a living biofilm
}

\author{
Paul Stoodley, PhD, Dirk deBeer, PhD, Mark Longwell, Laura Nistico, PhD, \\ Luanne Hall-Stoodley, PhD, Bruce Wenig, MD, and Yosef P. Krespi, MD, \\ Pittsburgh and Allegheny, PA; Bremen, Germany; and New York, NY
}

Sponsorships or competing interests that may be relevant to content are disclosed at the end of this article.

\section{ABSTRACT}

OBJECTIVE: To study the morphology and activity of tonsilloliths, demonstrating oxygen respiration, denitrification, and acidification on exposure to sucrose.

STUDY DESIGN: Tonsilloliths were extracted in atraumatic conditions during tonsillectomy from 16 adults and sent to two different laboratories for histological, bacteriological, and biofilm studies under sterile conditions.

SETTING: Multicenter laboratory study.

SUBJECTS AND METHODS: Multiple tonsilloliths from two patients examined by confocal microscopy and microelectrodes were used to measure aerobic/anaerobic respiration and acid production (dissolved oxygen, nitrous oxide, $\mathrm{pH}$ ) when exposed to saliva following addition of sucrose and fluoride.

RESULTS: Morphologically, tonsilloliths were similar to dental biofilms, containing corncob structures, filaments, and cocci. Microelectrodes showed that the microorganisms respired oxygen and nitrate. The oxygen concentration in the center of the tonsillolith was depleted to approximately one-tenth of that of the overlying fluid. The addition of sucrose resulted in acid production within the tonsillolith, dropping the $\mathrm{pH}$ from 7.3 to 5.8. The data showed stratification with oxygen respiration at the outer layer of tonsillolith, denitrification toward the middle, and acidification toward the bottom. The depletion of oxygen and acid production following addition of sucrose may allow the proliferation of anaerobic/acidophilic bacteria. Fluoride suppressed acid production in the presence of sucrose.

CONCLUSIONS: Tonsilloliths exhibit biofilm structure and the formation of chemical gradients through physiological activity. Although tonsillectomy is an option for treating cryptic infections, understanding the morphology and biofilm characteristics of tonsilloliths may stimulate scientists to use limited or targeted remedies in the future.

(C) 2009 American Academy of Otolaryngology-Head and Neck Surgery Foundation. All rights reserved.

B iofilm formation is increasingly being recognized as a virulence factor for infections associated with the pharynx and upper airway. ${ }^{1}$ Biofilms are assemblages of bacteria that are attached to surfaces (in the case of otolaryngolog- ical infections, epithelial and mucosal surfaces). Biofilms have been identified on middle ear epithelium in pediatric patients suffering with otitis media, ${ }^{2}$ on adenoid and tonsil tissue, ${ }^{3,4}$ and in the sinuses of patients suffering from rhinosinusitis. ${ }^{5}$

Biofilms are most commonly distinguished from bacterial colonization by the presence of an extracellular matrix enveloping the bacteria and structural features such as cell clusters, towers, and evidence of stratification suggesting a developmental process of a bacterial community, rather than the casual attachment of single cells. Scanning electron microscopy has been most commonly used to identify biofilms associated with clinical specimens. Confocal microscopy has the advantage that specific fluorescent staining can be used to identify chemical components (ie, proteins, nucleic acids, carbohydrates), bacteria species (by fluorescent in situ hybridization, FISH), and viability on fully hydrated specimens. $^{2,4}$

Bacteria in biofilms are difficult to kill with antibiotics and, because they are localized, can also act as a nidus for acute episodes. ${ }^{6}$ These characteristics are increasingly associated with the high recurrence rate and chronicity associated with many otolaryngological infections. ${ }^{1}$ Another characteristic feature of biofilms is the development of chemical gradients due to consumption of nutrients (such as oxygen) and the production of metabolic end products such as lactic acid, which in turn creates microniches within the biofilm, allowing the coexistence of many different types of bacteria. For example, the consumption of oxygen by aerobic bacteria at the top of dental biofilms creates underlying anaerobic regions that can then be occupied by anaerobic pathogens..$^{7-9}$

Tonsilloliths are another feature of the pharynx that appears to have characteristics in common with biofilms, particularly with dental biofilms. Tonsilloliths act as a localized concentration of aerobic and anaerobic bacteria, they calcify over time, progressing from soft gels to hard "stones," and they are often associated with inflammation (ie, in gingivitis and tonsillar inflammation). ${ }^{10,11}$ Tonsilloliths form within tonsillar crypts and are associated with halitosis, thought to be caused by the release of volatile sulfur compounds pro-

Received February 4, 2009; revised May 5, 2009; accepted May 14, 2009. 
duced from sulfur metabolism of anaerobic bacteria. ${ }^{11,12}$ Tonsilloliths are also associated with chronic cryptic tonsillitis, which is the most common indication for adult tonsillectomy.

It was the goal of the present study to determine whether tonsilloliths could be considered biofilms by using conventional thin section histology on 16 patients, with more detailed analysis on a subset of multiple tonsilloliths from both tonsils of two patients by using confocal microscopy and dissolved oxygen $(\mathrm{DO}), \mathrm{pH}$, and nitrous oxide $\left(\mathrm{N}_{2} \mathrm{O}\right)$ microelectrodes for respiration, acid fermentation and denitrification, respectively. Further, we wished to assess the influence of fluoride ion $\left(\mathrm{F}^{-}\right)$on the reduction of acidic regions in the tonsillolith. Fluoride is a common ingredient of dentifrices used for caries control, and we have recently shown that sodium fluoride $(\mathrm{NaF})$ reduced sucrose-stimulated $\mathrm{pH}$ drop in dental biofilms. ${ }^{7}$

\section{MATERIALS AND METHODS}

\section{Collection of Tonsilloliths}

After obtaining institutional review board approval and informed consent, tonsilloliths were collected randomly from 16 young adult patients undergoing elective tonsillectomy for chronic tonsillitis. None of these patients had any acute infections or antibiotic therapy in the preceding 3 months. First, prior to tonsillectomy, tonsilloliths alone were extracted by blunt pressure or they were dissected and removed in atraumatic technique in situ within tonsil crypts, stored in physiological saline, and shipped under sterile conditions to the laboratories for microbiological biofilm studies (Allegheny-Singer Research Institute, Pittsburgh) for whole-organ histopathological examination (St Lukes Roosevelt Hospital, New York).

\section{Thin Section Histology}

Tonsil specimens were oriented and sectioned in a manner to best demonstrate the crypts and tonsilloliths. The specimens were thinly sectioned, stained with hematoxylin-eosin (H\&E), and examined with light microscope by a senior surgical pathologist.

\section{Confocal Microscopy}

Tonsilloliths from two patients were selected for more indepth analysis by confocal microscopy. Individual tonsilloliths were mounted by placing them on a thin layer of cooled molten agar $(15 \%)$ in a $35-\mathrm{mm}$ Petri plate. The tonsilloliths were gently placed onto the agar with tweezers, avoiding contact with the intended viewing region, but they were not submerged. The specimens were stained according to manufacturer's instructions by pipetting approximately $50 \mu \mathrm{L}$ of BacLight Live Dead kit (Invitrogen, Carlsbad, CA) onto each tonsillolith. After 30 minutes of incubation at room temperature in the dark, the petri plate was flooded with Hanks balanced salt solution with calcium chloride and magnesium chloride, but without phenol red (cat\# 14025, Invitrogen). The tonsilloliths were observed with a Leica DM RXE microscope attached to a TCS SP2 AOBS confocal system (Leica Microsystems, Exton, PA); a $\times 63$ long working distance water immersion objective was used, thus ensuring that the specimens were never dehydrated.

\section{Microelectrode Studies}

Individual tonsilloliths collected from two patients were mounted in cooled molten agar as described in previous text. Diluted saliva (10\% in $1 \%$ phosphate buffer solution, PBS) was flowed over the tonsilloliths at a flow rate of 0.5 $\mathrm{mL} / \mathrm{min}$ with the use of a peristaltic pump (Ismatec; Cole Parmer Instrument Co., Vernon Hills, IL). The unstimulated saliva was collected on ice and pooled from six young healthy volunteers of both sexes, with good oral hygiene and no detectable oral malodor by organoleptic methods. The saliva was used within 3 hours of collection, diluted in 1 percent PBS, and then spun down at $3500 \mathrm{rpm}$ for 25 minutes. The supernatant was decanted. We diluted the saliva to lower the viscosity so that we could pump the fluid across the tonsilloliths for microelectrode measurements at a flow rate of $0.5 \mathrm{~mL} / \mathrm{min}$. The chamber was positioned on a $37^{\circ} \mathrm{C}$ heater. Because we were interested in determining whether denitrification (an anaerobic respiration) was occurring in the tonsilloliths, we measured the nitrate concentration in the undiluted saliva with a nitrate microelectrode. ${ }^{8}$ The microelectrode was calibrated with the use of potassium nitrate $\left(\mathrm{KNO}_{3}\right)$ between 0 and $500 \mu \mathrm{M}$. The concentration of nitrate in the undiluted saliva was $763 \mu \mathrm{M}$. Because the measured saliva nitrate from our volunteers fell close to the median found in a clinical study of 209 people, ${ }^{13}$ we decided to use it as a representative physiological concentration.

Thereafter, $\mathrm{KNO}_{3}$ was added to the diluted saliva to make up to $763 \mu \mathrm{M} \mathrm{NO}_{3}{ }^{-}$ion. For the measurement of physiological activity in response to sugar, a pulse of sucrose $(2.5 \%$ or $10 \%)$ was added to the medium. Physiological activity in the tonsilloliths was measured with either a 1) dissolved oxygen, 2) $\mathrm{pH}$, or 3) $\mathrm{N}_{2} \mathrm{O}$ microelectrode.

Microelectrodes were prepared and calibrated as previously described ${ }^{8}$ with measurements performed by using a semiautomated setup. Concentration measurements were made at various depths above, and into, the tonsilloliths. The location of the surface of the tonsillolith was determined by observation with a dissecting microscope and designated as depth 0 . The development of an oxygen profile with anaerobic regions within the tonsilloliths was assumed to be indicative of aerobic respiration; the production of acid was indicative of acid fermentation; and the production of $\mathrm{N}_{2} \mathrm{O}$ was indicative of denitrification.

\section{Conversion Rates at Different Depths in the Tonsilloliths}

For calculation of the local conversion rates within the biofilm, a stepwise algorithm was used as described thor- 
oughly by Gieseke et al. ${ }^{9}$ To determine where acidification was occurring within the tonsillolith, we calculated rate data in terms of the relative $\mathrm{H}^{+}$ion production or consumption from the $\mathrm{pH}$ data, because the actual proton concentration is a function of buffering. First, we converted $\mathrm{pH}$ to $\mathrm{H}^{+}$ concentration using $\left[\mathrm{H}^{+}\right]=10^{-\mathrm{pH}}\left(\mathrm{mol} \mathrm{l}^{-1}\right)$. We then expressed the production rate at different depths in the tonsilloliths and under the various conditions as relative values; those values were expressed as a percentage of the maximum rate.

\section{RESULTS}

\section{Histology}

Examination of the tonsil specimens stained with H\&E under low magnification demonstrated tonsil crypts and surrounding benign lymphoid hyperplasia (Fig 1). Within the crypts tonsilloliths of various sizes were documented in early or mature stages of their development. A layer of fibrinous debris and inflammatory cells was identified between the tonsillolith and the crypt epithelium. Squamous epithelium of the tonsil surface was noted to extend toward the lining of the tonsil crypt. At the depth of the tonsillar crypt, some areas of mucosal changes from squamous epithelium to so-called lymphoepithelium were noted. These benign-appearing lymphoid cells overran (and obscured) the nonkeratinizing squamous epithelium; this type of epithelium can be seen lining the inflamed cryptic areas adjacent to tonsilloliths. Free mature tonsilloliths appeared as a round amorphous mass with a basophilic appearance. In the early stages of tonsillolith formation the biofilm was found to be adherent to the crypt epithelium. At high magnification the tonsilloliths were composed of a dense matrix and large quantities of microbial colonies composed of rods and cocci.

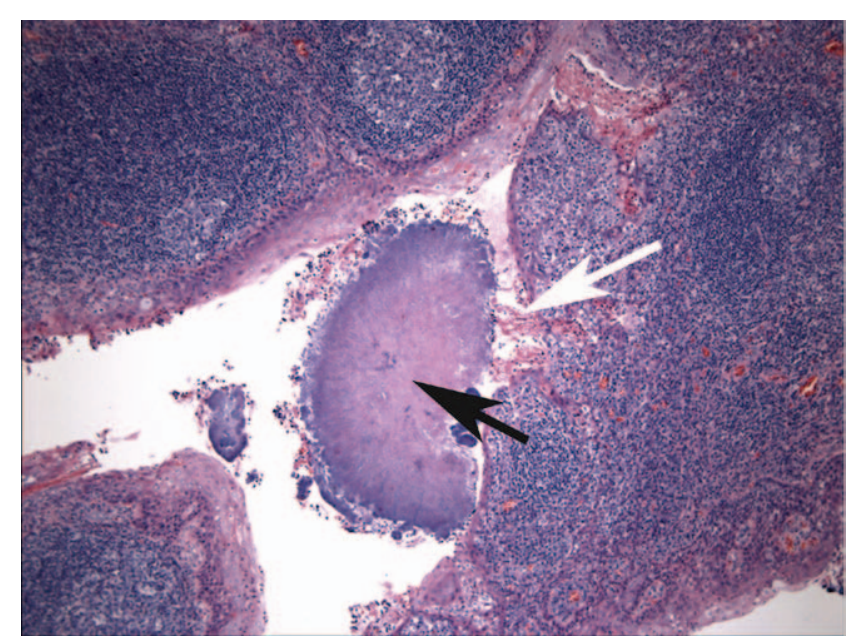

Figure 1 Tonsillolith (black arrow) within tonsillar crypt lined by squamous epithelium with reactive lymphoid hyperplasia. Fibrinous debris and inflammatory cells (white arrow).

\section{Confocal Microscopy}

The tonsilloliths were composed of densely packed bacteria including rods, cocci, and filamentous bacteria held together within an extracellular matrix (Fig 2A). In some places there was evidence of stratification, with fusiform rod-shaped bacteria concentrated on the outside and cocci on the inside layer (Fig 2B). The fusiform rods had a distinctive morphology consistent with that of Fusobacterium nucleatum. The composition of the matrix was undetermined because the reflected imaging technique was nonspecific. We also observed corncob structures consisting of cocci surrounding filamentous bacteria (Fig 3). Corncob structures are a common feature of dental biofilms and have been shown to consist of various bacteria including $F$. nucleatum (filamentous gram-negative rods) and Streptococcus sanguis (grampositive cocci). ${ }^{14}$

\section{Microelectrode Studies}

The tonsilloliths consumed oxygen when exposed to unsupplemented 10 percent saliva, so that at $0.6 \mathrm{~mm}$ depth the DO was reduced to approximately 30 percent of air saturation (Fig 4A). The absence of $\mathrm{N}_{2} \mathrm{O}$ production suggested that there was no denitrification (Fig 4B). When the 10 percent saliva was supplemented with sucrose, aerobic respiration, denitrification, and acid fermentation were stimulated. The oxygen concentration within the tonsillolith was further reduced to approximately 10 percent of air saturation (Fig 4A). The $\mathrm{pH}$ dropped from 7.2 to a minimum of approximately 6.3 at a depth of $0.2 \mathrm{~mm}$ with 2.5 percent sucrose and to 5.7 with 10 percent sucrose (Fig 4C). When $\mathrm{NaF}$ was added to the 10 percent saliva/10 percent sucrose medium, the $\mathrm{pH}$ increased, suggesting that the fluoride was inhibiting acid fermentation. Aerobic respiration was maximal in the surface layer down to a depth of $125 \mu \mathrm{m}$; denitrification was greatest between $50 \mu \mathrm{m}$ and $200 \mu \mathrm{m}$; and acid fermentation occurred predominantly at depths greater than $100 \mu \mathrm{m}$.

\section{DISCUSSION}

The thin histology sections and confocal imaging revealed that the tonsilloliths contained a high density of bacteria, a diversity of cell morphologies showing that they were polymicrobial in nature, and that they were stratified. The fusiform morphology and corncob structures suggested that $F$. nucleatum was present and the images were similar to those of dental biofilms. ${ }^{15}$ In future studies FISH might be employed to confirm the identification of $F$. nucleatum. Tsuneishi et $\mathrm{al}^{11}$ had detected $F$. nucleatum in tonsilloliths by $16 \mathrm{~S}$ ribosomal bacterial DNA sequencing and noted filaments in scanning electron micrographs. $F$. nucleatum is an obligate anaerobe that can produce volatile sulfur compounds associated with bad breath. ${ }^{16}$ Noting that the filaments were in the interior of the tonsillolith, these authors hypothesized that this was because the interior was presum- 


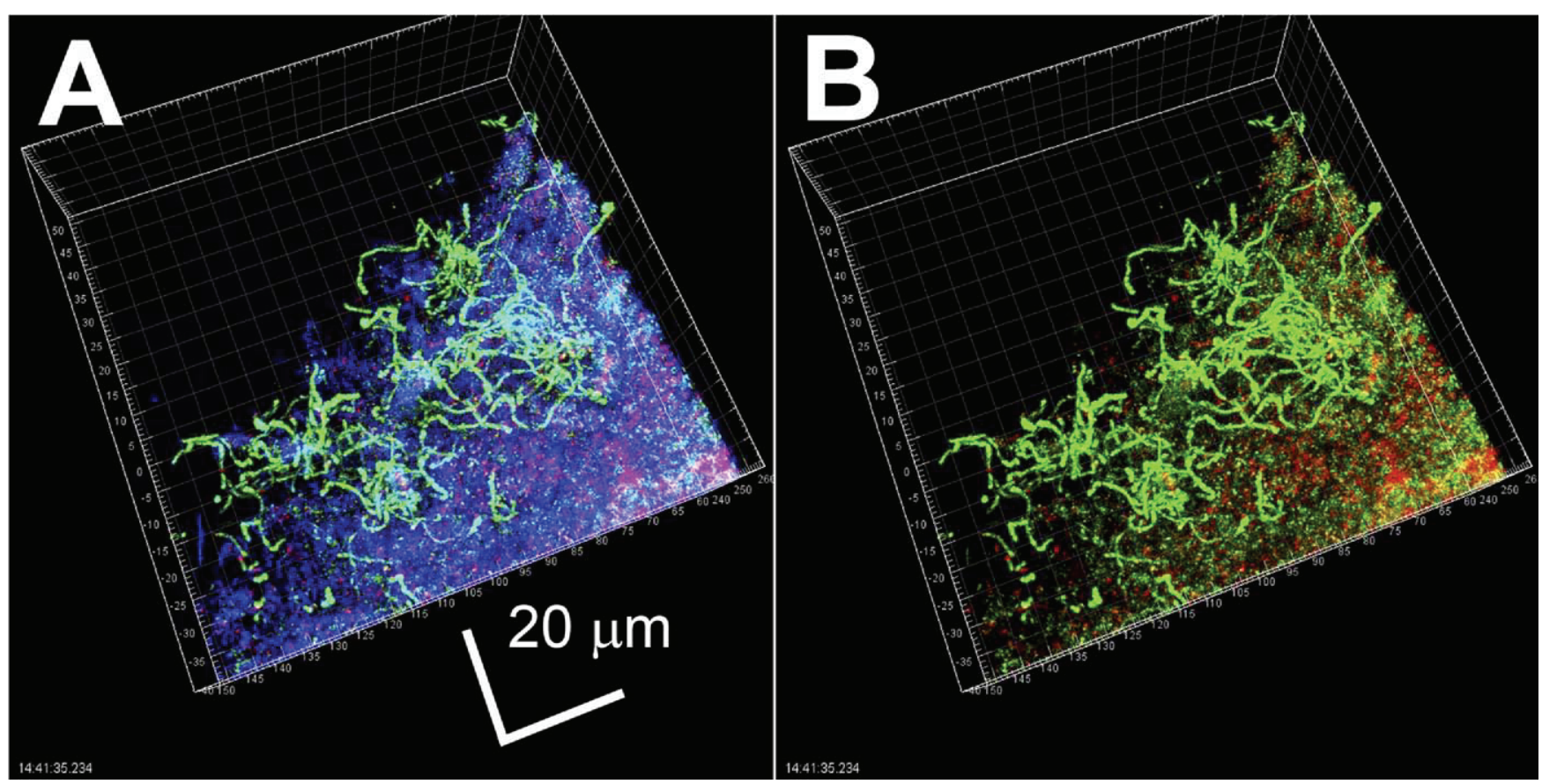

Figure 2 Confocal microscopy of tonsillolith. (A) Live (green) and dead (red) bacteria within matrix (blue). (B) Subtracting the matrix shows live filamentous bacteria on the surface, with rods and cocci deeper.

ably anaerobic and therefore a favorable environment for anaerobes. In the present study we observed the fusiform bacteria on the surface of the tonsillolith.

The microelectrode data showed that the bacteria in the tonsilloliths were metabolically active and that oxygen consumption in the top layers depleted oxygen deeper in the tonsillolith. The addition of sucrose stimulated oxy-

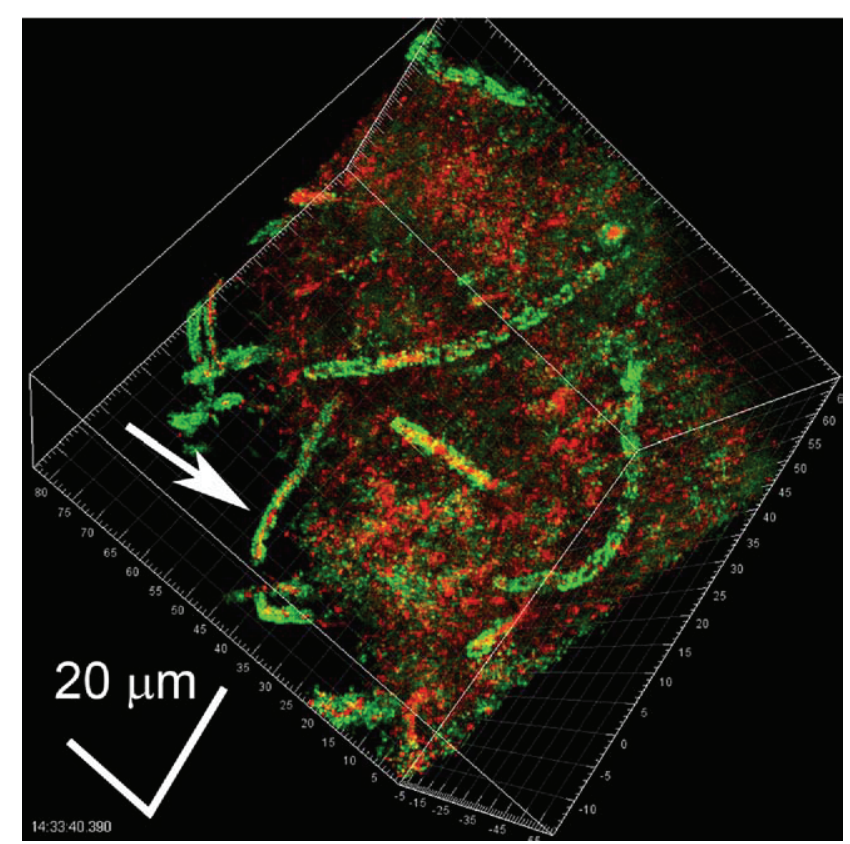

Figure 3 Corncob structures (white arrow) of green cocci surround red filamentous bacteria. Cocci predominantly surround the corncobs. gen consumption and acid fermentation in a similar manner to that seen in dental biofilms. ${ }^{7}$ However, it was interesting to note that even at a depth of $600 \mu \mathrm{m}$ the dissolved oxygen concentration was still greater than 10 percent of saturation. In biofilms containing aerobic bacteria, oxygen is usually almost fully consumed at depths of greater than $100 \mu \mathrm{m}$. The higher concentrations that we measured in the present study might be explained by either a relatively low population of active aerobic bacteria or the presence of channels through the tonsillolith, which might have transported aerated medium; however, we did not note an extensive network of channels during confocal examination. The microelectrode profiles indicated that there was a stratification of physiological activity with aerobic respiration at the top of the tonsillolith, acid fermentation deeper in the tonsillolith, and an overlapping denitrifying zone in between. The acidified nitrite decomposes to nitric oxide (NO), which then has a bactericidal effect. ${ }^{17}$ To defend against the highly reactive $\mathrm{NO}$, which is also produced by human phagocytes, some bacteria possess enzymes with NO reductase activity, which reduces $\mathrm{NO}$ to $\mathrm{N}_{2} \mathrm{O} .{ }^{18}$ It is therefore possible that the observed $\mathrm{N}_{2} \mathrm{O}$ production we measured in the acidic region of the tonsillolith might not be attributable to just denitrification for energy, but may also be attributable to a NO detoxification defense strategy by competing bacteria within the tonsillolith. The microelectrode data were useful in demonstrating that the tonsillolith bacteria were capable of forming chemical gradients and that there was metabolic stratification (a characteristic of biofilms); however, the ex situ condition, removed from host immunity and creating an altered surrounding environment, will almost certainly have 


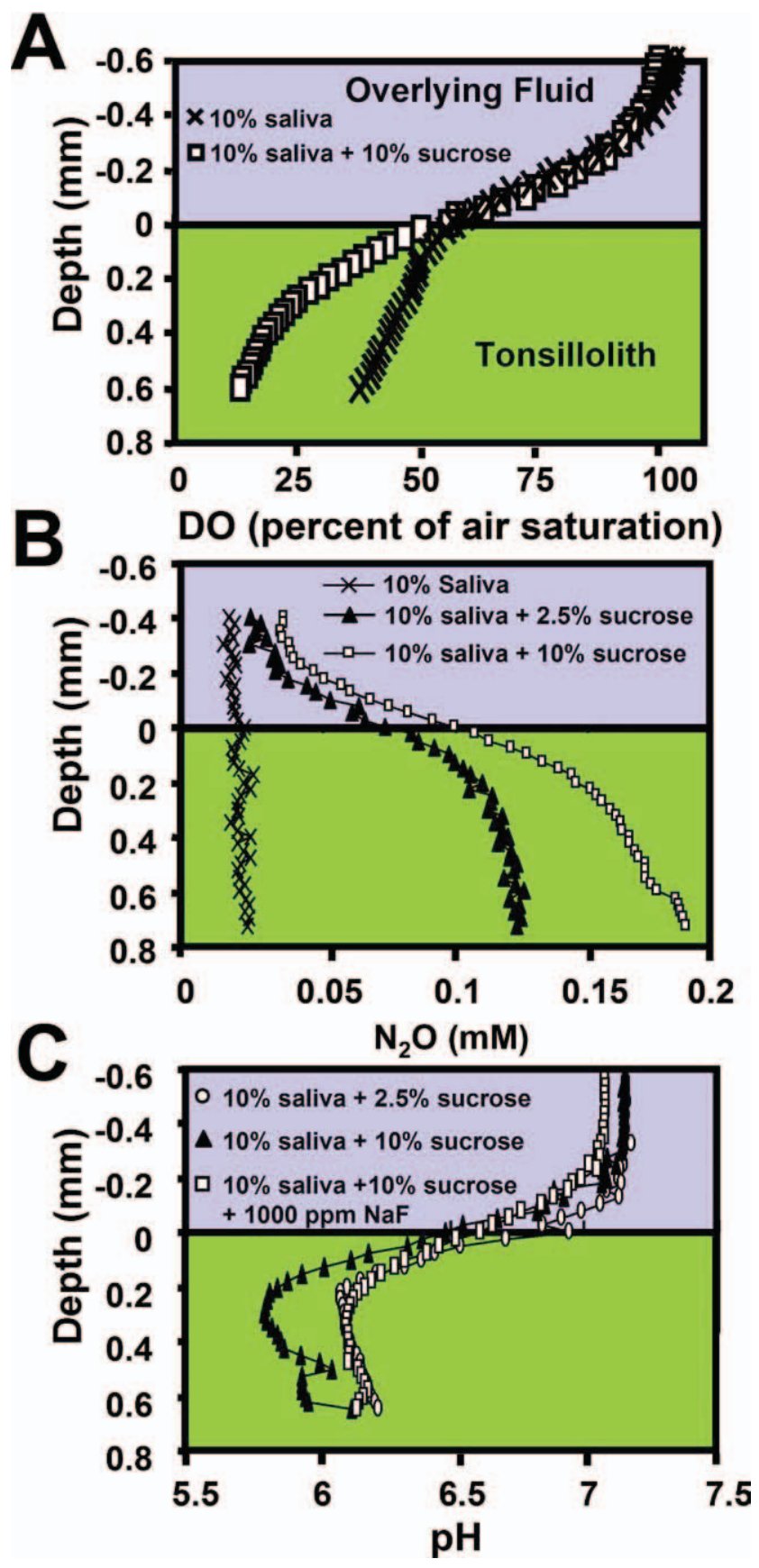

Figure 4 Metabolic activity of bacteria. (A) Oxygen consumption; (B) $\mathrm{N}_{2} \mathrm{O}$ production (denitrification); (C) $\mathrm{pH}$. Sucrose caused the $\mathrm{pH}$ to drop; $\mathrm{NaF}$ inhibited acid fermentation, raising $\mathrm{pH}$.

a significant impact on activity, so absolute values of conversion rates and concentrations should not be taken as indicative of the in vivo condition. The purpose here was not to suggest we could extrapolate our data to determine exact conversion rates or concentrations in vivo, but to use microelectrodes to demonstrate that the tonsilloliths were capable of metabolic activity consistent with biofilms, thus supporting our conclusions from histological analysis.

Finally, we added fluoride to assess the influence on acid fermentation. Fluoride reversed the $\mathrm{pH}$ drop caused by a pulse of sucrose from 5.7 at a depth of $200 \mu \mathrm{m}$ to the original 6.2 in the presence of 10 percent saliva alone. This response was similar to that observed in dental biofilms; taken together our data suggest that mechanical, optical, ${ }^{19}$ and/or chemical control strategies developed to control dental biofilms might be considered for potential treatments for tonsilloliths.

Finally, it should be noted that although microelectrodes have been used for environmental biofilms and for ex vivo dental biofilms grown on coupons,${ }^{20}$ to our knowledge the present study is the first to employ microelectrodes to measure chemical gradients in biofilms grown on a mucosal surface.

\section{CONCLUSIONS}

Tonsilloliths are microbial biofilms that exhibit structural heterogeneity, and the physiological activity of these biofilms results in the formation of chemical gradients and microniches. Currently, complete or intracapsular tonsillectomy is considered an option for treating chronic cryptic infections in adults; however, understanding the morphology and biofilm characteristics of tonsilloliths may stimulate clinicians to conduct randomized controlled trials of adequate sample size to assess the efficacy of using less invasive methods for treating chronic cryptic tonsillitis in the future.

\section{ACKNOWLEDGEMENTS}

Gaby Eickert, Ines Schroeder, Karin Hohmann, Max Planck Institute for Marine Microbiology: made the microelectrodes; Drs Anil Arora and Victor Kizhner, St Lukes Roosevelt Hospital: collected specimens; Prof Willy Verstraete, University Gent, Belgium: provided ideas on the role of nitrate reduction to inhibit competitor bacteria.

\section{AUTHOR INFORMATION}

From the Center for Genomic Science, Allegheny-Singer Research Institute (Drs Stoodley and Hall-Stoodley), Pittsburgh; the Department of Microbiology and Immunology, Drexel University College of Medicine (Drs Stoodley, Longwell, Nistico, and Hall-Stoodley), Allegheny Campus; the Max Planck Institute for Marine Microbiology (Dr deBeer), Bremen; and the Departments of Pathology and Laboratory Medicine (Dr Wenig) and Otolaryngology (Dr Krespi), St Luke's Roosevelt Hospital, Columbia University, New York.

Corresponding author: Yosef P. Krespi, MD, Department of Otolaryngology, St Luke's Roosevelt Hospital, 425 West 59th St., 10th Flr, New York, NY, 10019.

E-mail address: hnsg@aol.com.

\section{AUTHOR CONTRIBUTIONS}

Paul Stoodley, confocal microscopy, microelectrodes, editing; Dirk DeBeer, microelectrodes; Mark Longwell, microelectrodes; Laura Nistico, microbiology, confocal microscopy; Luanne Hall-Stoodley, micro- 
biology, editing; Bruce Wenig, histology; Yosef Krespi, original idea, histology, review.

\section{DISCLOSURES}

\section{Competing interests:}

Paul Stoodley, Phillips Oral Healthcare: research funding, consultant, and scientific advisory board; Valam: consultant; Dirk DeBeer, none; Mark Longwell, none; Laura Nistico, none; Luanne Hall-Stoodley, none; Bruce Wenig, none; Yosef Krespi, ARC Laser: unpaid consultant; Valam: director and scientific board member; Lumenis: consultant, research and development funding.

Sponsorships: Funding in part by Philips Oral Healthcare, Valam, and Allegheny-Singer Research Institute. Sponsors provided equipment and partial funding for the study.

Sponsors and funding organizations did not design or conduct the study; participate in the collection, analysis, and interpretation of data; or write or approve the manuscript.

\section{REFERENCES}

1. Post JC, Hiller NL, Nistico L, et al. The role of biofilms in otolaryngologic infections: update 2007. Curr Opin Otolaryngol Head Neck Surg 2007;15:347-51.

2. Hall-Stoodley L, Hu FZ, Gieseke A, et al. Direct detection of bacterial biofilms on the middle-ear mucosa of children with chronic otitis media. [Clinical investigation]. JAMA 2006;296:202-11.

3. Chole RA, Faddis BT. Anatomical evidence of microbial biofilms in tonsillar tissues: a possible mechanism to explain chronicity. Arch Otolaryngol Head Neck Surg 2003;129:634-6.

4. Nistico L, Gieseke A, Stoodley P, et al. Fluorescence in-situ hybridization for the detection of biofilm in the middle ear and upper respiratory tract mucosa. Methods Mol Biol 2009;493:191-215.

5. Prince AA, Steiger JD, Khalid AN, et al. Prevalence of biofilmforming bacteria in chronic rhinosinusitis. Am J Rhinol 2008;22: $239-45$.
6. Parsek MR, Singh PK. Bacterial biofilms: an emerging link to disease pathogenesis. Annu Rev Microbiol 2003;57:677-701.

7. Stoodley P, Wefel J, Gieseke A, et al. Interactions between fluoride, biofilm plaque and hydrodynamics on caries. JADA 2008;139:118290 .

8. Kühl M, Revsbech NP. Biogeochemical microsensors for boundary layer studies. In: Boudreau B, Jørgensen BB, editors. The benthic boundary layer. Oxford: Oxford University Press; 2000. p. 180-210.

9. Gieseke A, Bjerrum L, Wagner M, et al. Structure and activity of multiple nitrifying bacterial populations co-existing in a biofilm. Environ Microbiol 2003;5:355-69.

10. Myers NE, Compliment JM, Post JC, et al. Tonsilloliths a common finding in pediatric patients. Nurse Pract 2006;31:53-4.

11. Tsuneishi M, Yamamoto $\mathrm{T}$, Kokeguchi $\mathrm{S}$, et al. Composition of the bacterial flora in tonsilloliths. Microbes Infect 2006;8:2384-9.

12. Krespi YP, Shrime MG, Kacker A. The relationship between oral malodor and volatile sulfur compound-producing bacteria. Otolaryngol Head Neck Surg 2006;135:671-6.

13. Doel JJ, Hector MP, Amirtham CV, et al. Protective effect of salivary nitrate and microbial nitrate reductase activity against caries. Eur J Oral Sci 2004;112:424-8.

14. Lancy P, Dirienzo JM, Appelbaum B, et al. Corncob formation between Fusobacterium nucleatum and Streptococcus sanguis. Infect Immun 1983;40:303-9.

15. Rickard AH, Gilbert P, High NJ, et al. Bacterial coaggregation: an integral process in the development of multi-species biofilms. Trends Microbiol 2003;11:94-100.

16. Pianotti R, Lachette S, Dills S. Desulfuration of cysteine and methionine by Fusobacterium nucleatum. J Dent Res 1986;65:913-7.

17. Xu J, Xu X, Verstraete W. The bactericidal effect and chemical reactions of acidified nitrite under conditions simulating the stomach. J Appl Microbiol 2001;90:523-9.

18. Saraiva LM, Vicente JB, Teixeira M. The role of the flavodiiron proteins in microbial nitric oxide detoxification. Adv Microb Physiol 2004;49:77-129.

19. Krespi YP, Stoodley P, Hall-Stoodley L. Laser disruption of biofilm. Laryngoscope 2008;118:1168-73.

20. Zaura E, ten Cate JM. Dental plaque as a biofilm: a pilot study of the effects of nutrients on plaque and dentin demineralization. Caries Res 2004;38(suppl 1):9-15. 